\title{
POSSIBILITIES OF USING LIQUEFIED OIL GAS IN TRANSPORT
}

\author{
Algirdas Kuprys ${ }^{1}$, Jonas Kugelevičius ${ }^{2}$ \\ Laboratory of Energy Systems Research, Lithuanian Energy Institute, Breslaujos g. 3, \\ LT-44403 Kaunas, Lithuania \\ E-mails: ${ }^{1}$ kuprys@mail.lei.lt; ${ }^{2}$ jonask@mail.lei.lt \\ Received 10 May 2008; accepted 12 January 2009
}

\begin{abstract}
The trends of the input of an alternative type of fuel in the transport system of the European Union are analysed. Taking into account the measures of promoting liquefied petroleum gas (LPG) consumption in road transport, a bundle of specific variables was analysed to understand the consumers for making decision to use LPG in cars. It is revealed that the obtained models enable to evaluate the behaviour of consumers and conditioning transition to using an alternative type of fuel in transport industry. The proposed models were assessed conducting statistic and sensitivity analysis. The payoff of the additional equipment of the car was analysed considering the driven distance with an alternative type of fuel. The pay-off analysis of supplementary equipment depending on the ratio of standard and alternative fuel prices is presented.
\end{abstract}

Keywords: liquefied petroleum gas, hedonic model, price ratio, statistical analysis.

\section{Introduction}

A wide use of the alternative types of fuel in transport depends on its production and additional expenditure for its transportation and storage, payment policy and the acceptability of the final user to utilize alternative fuel (Kuglevičius et al. 2007; Tanczos and Torok 2007; Butkus et al. 2007; Lingaitis and Pukalskas 2008a, b). In any case, the production expenditure of alternative fuel is the price function derived from resources and the level of technology that enables to derive it. The implementation of Directive 2003/30/EC (2003) issued by the European Parliament and the European Council on 8 May 2003 on promoting the use of biofuels and other renewable fuels for transport apply various promoting measures to use the alternative types of fuel in transport. A number of economical experiments have been carried out regarding the impact of car characteristics on the price at the increase of environmental requirements and the change of fuel prices. The research results received by Jonson (2003) and Faiz et al. (1996) have revealed that the increasing prices of fuel enable to tackle strict environmental requirements. Hung (2006) notes that the main measure to apply cars to alternative fuel - LPG is to balance taxes giving priority to alternative fuel and paying subsidies to the equipment of alternative fuel. However, a wide use of the alternative types of fuel is stopped by the expenditure of alternative fuel production which usually exceeds the expenditure of producing standard fuel (gasoline, diesel) and an insufficient use of cars consuming different alternative fuel.

\section{Trends of LPG Expenditure in the EU}

There are a number of different engines using different kinds of alternative fuel. However, LPG, as a type of alternative fuel, is most widely used in the Otto cycle engines of internal combustion. LPG is an ecologic measure to reduce the amount of pollutants in the combustion products of car fuel. Other alternative types of fuel (biodiesel, ethanol or a mixture of methanol and gasoline, hydrogen, compressed or liquefied natural gas) in the engines of internal combustion are used very restrictedly in the EU. Data on using the alternative types of fuel in road transport (prices, consumption amounts) is very limited. Therefore, due to lack of statistical data, only LPG use in the Otto cycle engine of internal combustion in the EU countries will be analysed in the article.

Taking into account the indicated model of LPG use in cars, it is expedient to use statistical data in further analysis justifying relations among variables. For selecting typical values, we use the statistical data of EUROSTAT (2008) and International Energy Agency (IEA) statistic (2008). At this time, LPG is widely used for different needs in the EU (Fig. 1).

One of the exceptional fields is LPG use in road transport. As it can be seen, the final consumption of LPG increases more rapidly in transport. Within the analysed period, it increased by $35 \%$, whereas in other 


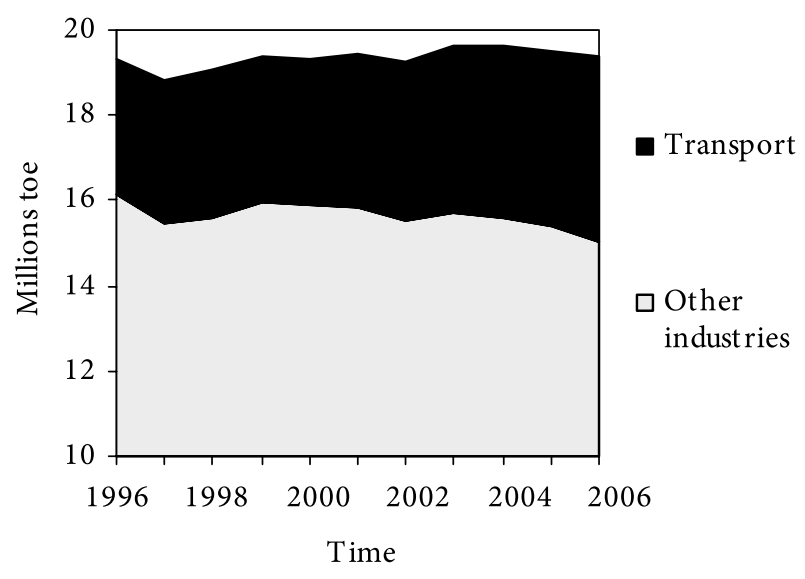

Fig. 1. The trends of final consumption LPG in the EU countries

industrial branches it remained almost constant and reduced only by $6 \%$. Detailed LPG consumption according to the information provided by the EU countries in 2006 is presented in Fig. 2.

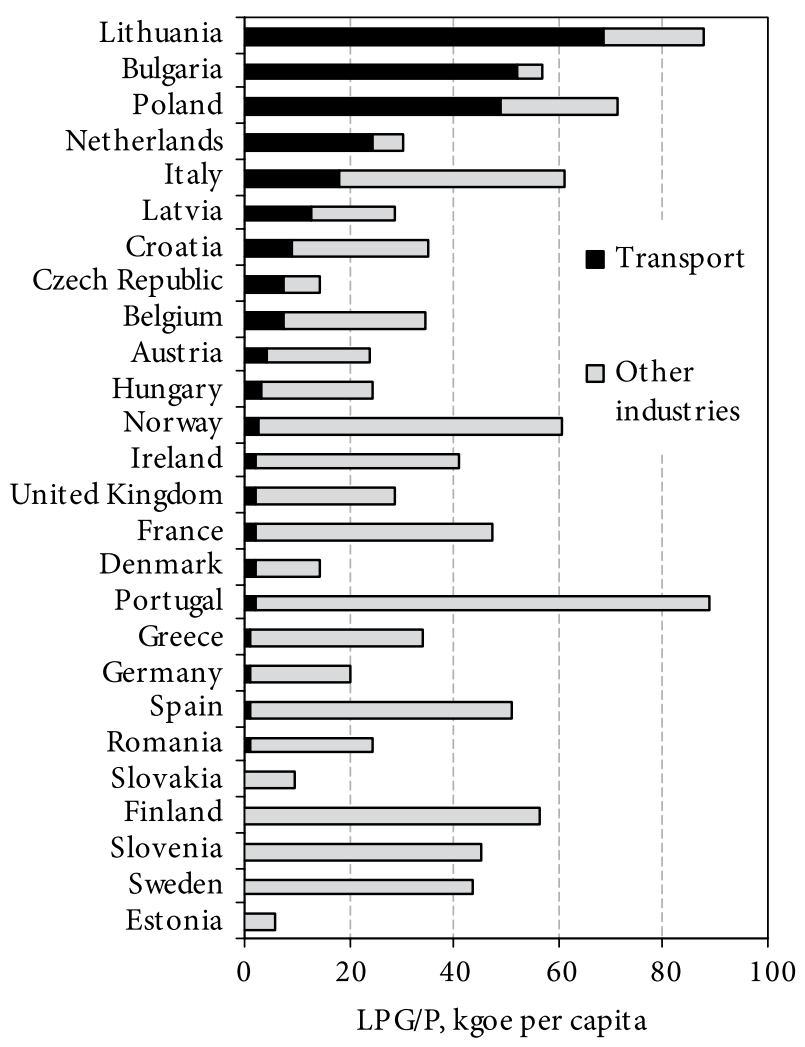

Fig. 2. The final consumption of LPG per capita in the selected EU countries

Due to a number of different reasons, the final consumption of LPG in different EU countries as well as in road transport changes in wide limits (Fig. 2). The biggest amount of LPG in transport is consumed in Lithuania, Bulgaria, Poland, Holland and Italy. In many EU countries, LPG in transport is not used at all or applied very restrictively (Slovenia, Slovakia and Finland). Also many countries (e.g. Estonia, Sweden) though use LPG in transport, no detailed statistical data is provided. Three EU countries including Holland, Italy and Poland consume 68\% of LPG in road transport and only due to Poland, LPG consumption in the EU countries substantialy increase (Fig. 3). Other EU countries consume only an insignificant part of LPG.

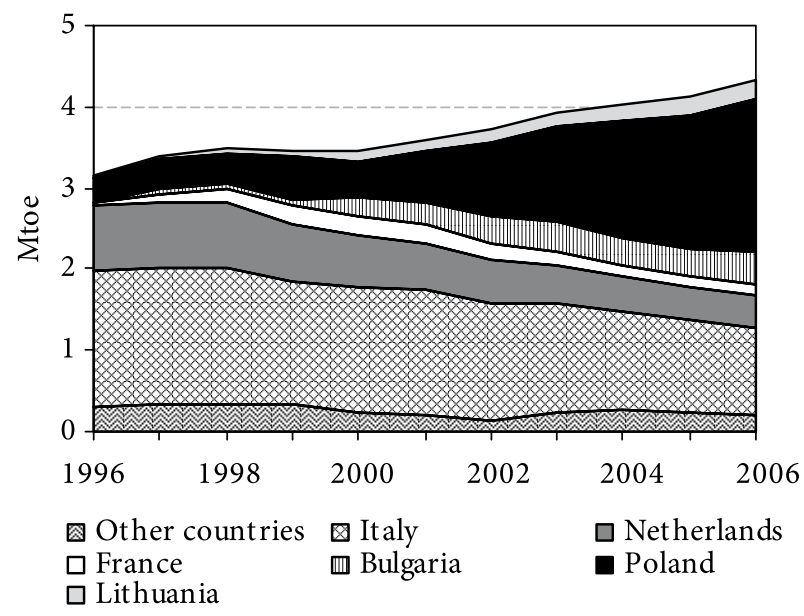

Fig. 3. LPG consumption in transport in various countries

One of the main indicators promoting LPG use in transport is the ratio of LPG and gasoline prices. The Governments of the EU countries differently estimate LPG application in transport. In most cases, this is related to the different types of gasoline and LPG prices, i.e. making discounts to LPG price while reducing taxes. This ratio in different EU countries fluctuates in the range from 0.49 to 0.85 (Fig. 4). Other impact measures (LPG equipment installation in cars using subsidies) of LPG installation in transport are more applied to public transport.

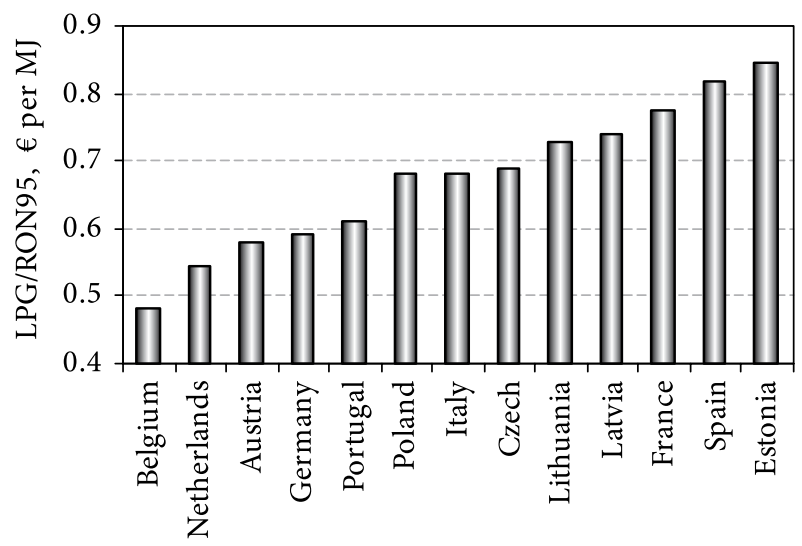

Fig. 4. The ratio of LPG and gasoline prices in the EU countries, 2006

The price of LPG equipment in cars depending on its complexity and the country of installation may vary in the range from 700 to $2500 €$. In general, it is comprised of two variables - the price of equipment itself and its installation to the car. It was not possible to find reliable sources able to evaluate the prices of LPG equipment and its installation, and thus in further analysis, only maximum and minimum prices were taken into account. 
When determining the model of LPG application in cars, it is expedient to use statistical data, justifying relations among variables in further analysis. While selecting the typical data, it is considered that the statistical dependence of LPG consumption on road transport is defined by variables. For this purpose, the typical data of various countries is transformed into the form relevant to the model (Table 1). Besides, aiming to use typical values in a regressive model and to reduce the number of variables, the following relative values were used:

- $P(X)$ - LPG consumption in road transport, MJ per capita,

- $X_{1}$ - The amount of GDP (at 1995 prices and exchange rates), $1000 €$ per capita,

- $X_{2}$ - Ratio of LPG and gasoline RON95 prices, $€$ per MJ,
- $X_{3}$ - Final consumption of LPG, MJ per capita,

- $X_{4}$ - Final consumption of all petroleum products, MJ per capita,

- $X_{5}$ - Final consumption of all petroleum products in transport, MJ per capita,

- $X_{6}$ - Ratio of the amount of individual cars older than ten years to total,

- $X_{7}-$ LPG consumption in road transport, average annual increase.

In the row of countries, the data on LPG price and consumption in transport is not presented. The information about the countries not found in the statistical basis of EUROSTAT and International Energy Agency (IEA) statistic will not be included into the future analysis.

Table 1. Data on using LPG in the road transport of the EU countries for regression analysis

\begin{tabular}{|c|c|c|c|c|c|c|c|c|}
\hline Country & $P(X)$ & $X_{1}$ & $X_{1}$ & $X_{1}$ & $X_{1}$ & $X_{1}$ & $X_{1}$ & $X_{1}$ \\
\hline \multicolumn{9}{|c|}{2004} \\
\hline Belgium & 8.46 & 25.4 & 0.46 & 21.8 & 1606 & 973 & 0.29 & -0.08 \\
\hline Czech & 7.34 & 5.0 & 0.69 & 18.7 & 666 & 545 & 0.55 & 0.03 \\
\hline Germany & 1.02 & 26.4 & 0.60 & 19.4 & 1106 & 737 & 0.31 & 0.07 \\
\hline Spain & 1.87 & 14.9 & 0.72 & 60.0 & 1237 & 894 & 0.39 & 0.00 \\
\hline France & 2.67 & 23.6 & 0.72 & 52.9 & 1195 & 786 & 0.32 & -0.10 \\
\hline Italy & 20.99 & 16.9 & 0.65 & 67.3 & 1024 & 738 & 0.39 & -0.07 \\
\hline Latvia & 10.78 & 2.9 & 0.70 & 25.4 & 562 & 432 & 0.85 & 0.06 \\
\hline Lithuania & 60.94 & 2.4 & 0.62 & 81.5 & 438 & 383 & 0.92 & 0.19 \\
\hline Netherlands & 25.53 & 25.1 & 0.50 & 32.1 & 1076 & 919 & 0.31 & -0.10 \\
\hline Poland & 37.63 & 4.1 & 0.62 & 63.7 & 456 & 287 & 0.56 & 0.29 \\
\hline Portugal & 2.10 & 10.4 & 0.66 & 99.0 & 1166 & 693 & 0.74 & 0.00 \\
\hline \multicolumn{9}{|c|}{2005} \\
\hline Belgium & 8.04 & 25.6 & 0.44 & 20.0 & 1582 & 936 & 0.29 & -0.06 \\
\hline Czech & 7.53 & 5.3 & 0.66 & 16.7 & 679 & 584 & 0.53 & 0.03 \\
\hline Germany & 1.07 & 26.7 & 0.59 & 19.7 & 1075 & 713 & 0.32 & 0.06 \\
\hline Spain & 1.14 & 15.2 & 0.77 & 57.2 & 1233 & 904 & 0.39 & -0.13 \\
\hline France & 2.44 & 23.7 & 0.75 & 51.5 & 1171 & 773 & 0.32 & -0.10 \\
\hline Italy & 19.35 & 16.7 & 0.63 & 66.2 & 1000 & 726 & 0.39 & -0.08 \\
\hline Latvia & 11.27 & 3.2 & 0.72 & 26.9 & 578 & 456 & 0.83 & 0.07 \\
\hline Lithuania & 65.98 & 2.6 & 0.69 & 87.0 & 470 & 409 & 0.91 & 0.14 \\
\hline Netherlands & 24.10 & 25.4 & 0.51 & 28.7 & 1067 & 918 & 0.31 & -0.10 \\
\hline Poland & 43.14 & 4.2 & 0.63 & 68.1 & 468 & 307 & 0.55 & 0.21 \\
\hline Portugal & 2.28 & 10.4 & 0.66 & 92.1 & 1003 & 665 & 0.73 & 0.05 \\
\hline \multicolumn{9}{|c|}{2006} \\
\hline Belgium & 7.61 & 25.7 & 0.48 & 34.6 & 1479 & 902 & 0.29 & -0.04 \\
\hline Czech & 7.71 & 5.6 & 0.69 & 14.3 & 673 & 595 & 0.51 & 0.04 \\
\hline Germany & 1.07 & 26.9 & 0.59 & 20.4 & 1089 & 709 & 0.33 & 0.02 \\
\hline Spain & 1.03 & 15.5 & 0.82 & 51.7 & 1213 & 918 & 0.39 & -0.16 \\
\hline France & 2.27 & 23.8 & 0.78 & 47.4 & 1147 & 779 & 0.32 & -0.08 \\
\hline Italy & 18.45 & 16.6 & 0.68 & 61.7 & 978 & 728 & 0.39 & -0.07 \\
\hline Latvia & 12.64 & 3.5 & 0.74 & 28.3 & 642 & 507 & 0.82 & 0.08 \\
\hline Lithuania & 68.17 & 2.8 & 0.73 & 87.3 & 490 & 435 & 0.91 & 0.10 \\
\hline Netherlands & 24.49 & 25.7 & 0.54 & 30.1 & 1062 & 945 & 0.31 & -0.06 \\
\hline Austria & 4.48 & 28.1 & 0.58 & 23.8 & 1377 & 883 & 0.34 & 0.06 \\
\hline Poland & 48.96 & 4.4 & 0.68 & 71.1 & 483 & 343 & 0.55 & 0.16 \\
\hline Portugal & 2.18 & 10.4 & 0.61 & 89.1 & 957 & 664 & 0.73 & 0.01 \\
\hline
\end{tabular}




\section{Hedonic Model of LPG use in Cars}

In general, manufacturers find important to evaluate the impact of product price on the consumer which is determined by the price of the sold item. The method analyzing the behaviour of customers in regard to the price of a good is called hedonic analysis. The main presumption of the method is that the customer buying different amounts and goods of different properties strives to maximize their use. The objective of the analysis is to join the variety of different factors and evaluate the price of a good as a unit.

Formalizing the priority of the customer to individual facility, the benefit function may be applied by Biderman et al. (2005):

$$
u=u(X, Z, \delta),
$$

where: $X$ - a supplementary equipment vector in volume car; $Z$ - the consumption of other material resources, $\delta-$ a vector defining customer's priority to equipment. From the benefit function, it is possible to indirectly get customer's need regarding car modernization (including the use of supplementary equipment).

$$
D=D(X, Y, u, \delta)
$$

where: $Y$ - the income of consumer.

The consumer will try to maximize benefit and will choose such $X$ and $Z$ values so that the function (2) would have maximum values.

$$
P(X) \leq \max \{X, Z, \delta\},
$$

where: $P(X)$ - a price vector attributed to equipment $X$, called 'hedonic price function'.

In general, this function is found as a multiple regression equation of many variables, McCormack (2003). The regression model may be determined modelling the relation of variables and determining their significance. The elimination of insignificant variables and the determination of the number of minimum variables was the objective of data regression analysis.

The performed regression analysis has revealed that the significance of various values such as GDP per capita, ratio of LPG and gasoline RON95 prices, LPG final consumption etc. (Table 1) depends on the expression of the function. The regression equations of the following form defining LPG use in transport were obtained:

$$
\begin{aligned}
& P_{1}(X)=b_{0}+b_{1} \cdot X_{4}+b_{2} \cdot X_{2}+b_{3} \cdot X_{3}, \\
& P_{2}(X)=b_{0}+X_{2} \cdot\left(b_{1} \cdot X_{2} \cdot X_{3}+b_{2} \cdot X_{4}^{2}+b_{4}\right)+ \\
& b_{3} \cdot X_{3}^{2} \cdot X_{4},
\end{aligned}
$$

or

$$
P_{3}(X)=b_{0}+b_{1} \cdot X_{2} \cdot X_{3}+b_{2} \cdot X_{2} \cdot X_{4}+b_{3} \cdot X_{2} .
$$

The data on LPG consumption in road transport in the EU countries was fitted with Steppan et al. (1998) software package. The summary of regression equations is presented in Table 2. It should be emphasized that due to a small number of data, the disperse of standard error is significant. The coefficient of determination $R^{2}$ shows the total variability of the over fitted models. In our case, $P_{2}(X)$ is a high prediction quality model. The lowest suitable model to predict $P(X)$ is $P_{1}(X)$. Durbin-Watson statistics is designed for assessing the autocorrelation of differences in regression analysis. These differences are always between 0 and 4 . In our case, $1.5<d<2.5$ and the test for the autocorrelations of residuals is inconclusive. The parameter collinearity outlines dependency among the variables. 0 points to linear dependency among the variables, whereas 1 means that there is no collinearity.

The values of the coefficients of regression equations and their evaluations of statistical hypotheses are given in Table 3 . The obtained $p$-values close to zero reveal that zero hypotheses are rejected and differences among the variables are obvious. The variance inflation factor of values reveals that the variables are not identical $(\mathrm{VIF}<10)$. Thus, it may be stated that the obtained

\begin{tabular}{|c|c|c|c|c|c|}
\hline $\begin{array}{c}\text { Func- } \\
\text { tion }\end{array}$ & $\begin{array}{c}\text { Coeffi- } \\
\text { cient }\end{array}$ & $P$ value & $-50 \%$ & $50 \%$ & VIF \\
\hline \multirow{4}{*}{ 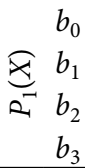 } & 100.74 & & 87.45 & 114.04 & \\
\hline & -0.04152 & $1.04 \mathrm{E}-06$ & -0.0462 & -0.0369 & 1.216 \\
\hline & -91.25 & 0.00113 & -108.56 & -73.94 & 1.256 \\
\hline & 0.298 & & & & 1.141 \\
\hline \multirow{5}{*}{$a^{\infty}$} & 107.09 & $4.21 \mathrm{E}-14$ & 101.70 & 112.47 & \\
\hline & -164.27 & $1.93 \mathrm{E}-12$ & -173.92 & -154.63 & 1.984 \\
\hline & 2.375 & $1.05 \mathrm{E}-14$ & 2.262 & 2.488 & 5.525 \\
\hline & $-2.40 \mathrm{E}-05$ & 1.57E-09 & $-2.59 \mathrm{E}-05$ & $-2.21 \mathrm{E}-05$ & 1.206 \\
\hline & $-7.70 \mathrm{E}-06$ & $1.35 \mathrm{E}-11$ & $-8.19 \mathrm{E}-06$ & $-7.21 \mathrm{E}-06$ & 3.976 \\
\hline \multirow{4}{*}{$\frac{\mathbb{\infty}}{R^{m}}$} & 74.98 & $5.543 \mathrm{E}-09$ & 68.62 & 81.34 & \\
\hline & -108.98 & $7.284 \mathrm{E}-08$ & -119.50 & -98.46 & 1.374 \\
\hline & 1.658 & $2.262 \mathrm{E}-15$ & 1.582 & 1.734 & 2.830 \\
\hline & $-9.35 \mathrm{E}-04$ & 7.67E-14 & $-9.84 \mathrm{E}-04$ & $-8.86 \mathrm{E}-04$ & 2.282 \\
\hline
\end{tabular}
regression equation is adequately described.

Table 2. Parameters for the model adequacy of regression equations

\begin{tabular}{lccc}
\hline \multicolumn{1}{c}{ Function } & $P_{1}(X)$ & $P_{2}(X)$ & $P_{3}(X)$ \\
\hline$|R|$ & 0.811 & 0.967 & 0.941 \\
$R^{2}$ & 0.658 & 0.935 & 0.885 \\
$R^{2}$ adjusted & 0.624 & 0.926 & 0.873 \\
Standard Error & 12.09 & 5.360 & 7.025 \\
\# Points & 34 & 34 & 34 \\
PRESS & 5877 & 1478 & 1889 \\
$R^{2}$ for Prediction & 0.542 & 0.885 & 0.853 \\
Durbin-Watson $d$ & 1.878 & 2.050 & 1.815 \\
First Order Autocorrelation & -0.048 & -0.107 & -0.003 \\
Collinearity & 0.740 & 0.161 & 0.339 \\
\hline
\end{tabular}

Table 3. The coefficients of regression equations and $\pm 50 \%$ confidence interval

The obtained regression equations reveal that there is a close connection between LPG consumption in road transport and the ratio of LPG and gasoline RON95 prices, the final consumption of LPG and the final consumption of all oil products. The significance of the predicted 
values $P_{1}(X)$ differs from $P(X)$ data (Fig. 5). Equation (5) evaluates LPG consumption more precisely, and thus forecasting LPG consumption in transport, we suggested using equations (5) or (6) which is simpler. In this case, equation 6 is the best option.

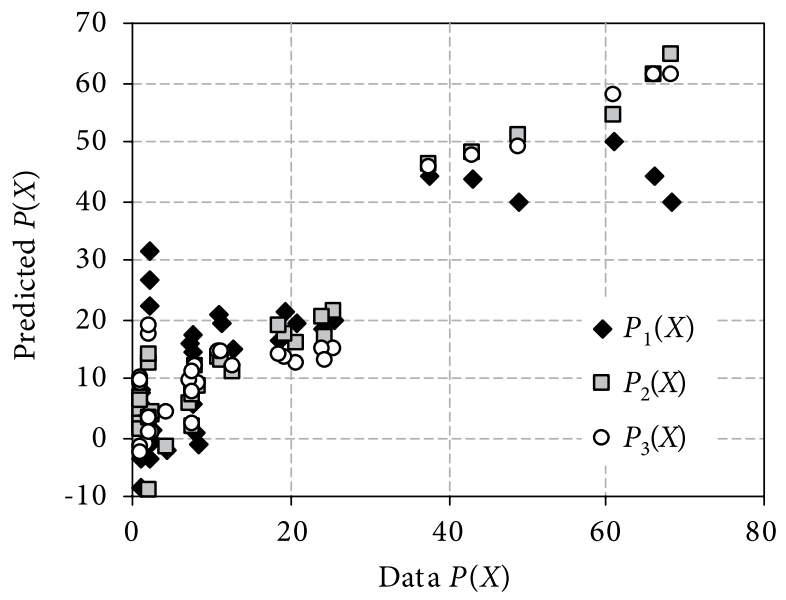

Fig. 5. A comparison of factual and predicted LPG consumption in transport

Due to relatively small amount of data function (6), the limits of confidence interval $\pm 50 \%$ significantly change the values of the function. The presented diagram (Fig. 6) describes the sensitivity coefficients of equation (6).

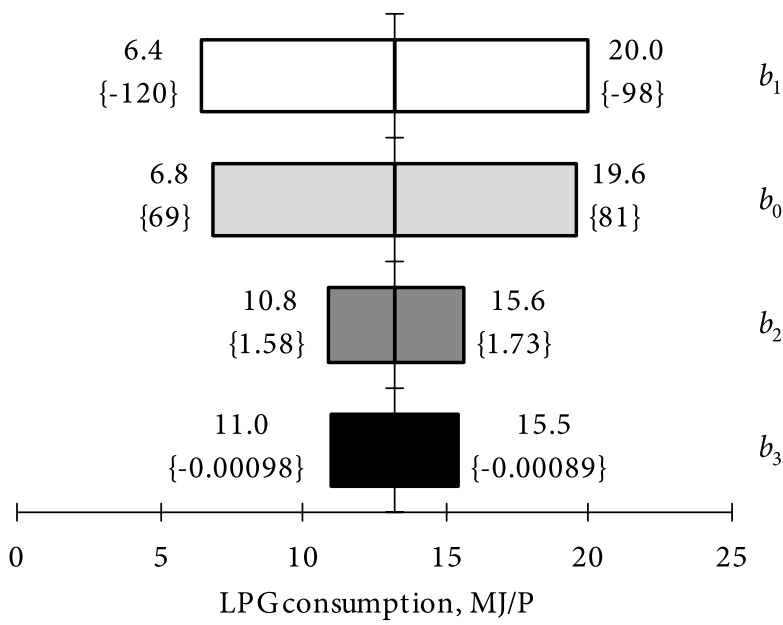

Fig. 6. The sensitivity of equation (6) with confidence interval $\pm 50 \%$ (Tornado diagram)

Tornado diagrams graphically display the results of the analyzed single-factor sensitivity values $b_{i}$ presented in Table 3. Figure 6 represents the effect of four parameters $b_{i}$ on the result $P_{3}(X)$. Minimum and maximum $b_{i}$ values correspond to confidence interval $\pm 50 \%$ (in parenthesis), whereas the values of function $P_{3}(X)$ lay in the $X$-axis at average $X_{2}, X_{2} \times X_{3}$ and $X_{3} \times X_{4}$ values. Coefficients $b_{1}$ and $b_{0}$ have the biggest impact on the solution, whereas the sensitivity of coefficients $b_{2}$ or $b_{3}$ is less significant. According to equation (6), the main influence on consumers to make a decision on using LPG in transport are the final consumption of all petroleum products, the ratio of LPG and gasoline RON95 prices and the final consumption of LPG. The interpretation of equation (6) is as follows. Keeping the level of other characteristics constant:

- one percent increase in the final consumption of all petroleum products gives a $3.23 \%$ increase in LPG consumption in transport,

- one percent increase in the ratio of LPG and gasoline RON95 prices gives a $1.43 \%$ increase in LPG consumption in transport,

- one percent increase in the final consumption of LPG gives a $0.65 \%$ decrease in LPG consumption in transport.

\section{Pay-off of LPG Equipment in the Car}

When installing LPG equipment in a car, a customer needs to know its pay-off time. Since LPG is installed in the car, pay-off time is more convenient to change with the driven distance:

$$
L=\frac{K}{B_{G} \cdot\left(B_{k}-S \cdot D_{k}\right)}, \mathrm{km}
$$

where: $K$ - expenditure for installing LPG fuel supply system in the car; in $€, B_{G}$ - gasoline consumption, $M J$ per km; $B_{k}$ - gasoline price, $€$ per MJ; $D_{k}$ - LPG price, $€$ per MJ; $S$ - the ratio of the amounts of gasoline and LPG fuel of the car using dual fuel. Ratio $S$ is derived from the ratio of the amounts of gasoline and LPG heat which is a constant size for gasoline internal combustion engines:

$$
S=\frac{Q_{G}}{Q_{D}} \cdot \frac{\eta_{G}}{\eta_{D}}
$$

$b_{0}$ where: $Q_{G}-$ gasoline and $Q_{D}-$ LPG calorific capacity, $\mathrm{MJ} / \mathrm{litre}$.

We have obtained these figures from International Energy Agency (IEA) statistic. Simpson (2005) estimate powertrain efficiency $\%$ with gasoline is $\eta_{G}=10.6$ and efficiency with LPG is $\eta_{G}=11.2$.

Analysing the pay-off of LPG equipment, the expenditure of car fuel makes 8.5-11.5 litre per $100 \mathrm{~km}$. LPG equipment and the price of installation in the car varies in a wide range. In general, installation price depends on the complexity of equipment and its implementation price that may vary in different EU countries. The minimum and maximum prices of gasoline RON95 and LPG prices were taken from International Energy Agency (IEA) statistic, whereas retail prices were obtained taking into account the ratios of gasoline and LPG prices presented in Fig. 7. Using the values presented in Table 4, the impact of different variables on the installation of LPG equipment in the car may be evaluated (Fig. 7).

At average values (Table 4), equipment pay-off is $19048 \mathrm{~km}$ (X-axis). This scheme distributed according to the downtrend order of variables the impact of which reveals that LPG and gasoline prices have the biggest influence on consumer's decision regarding the installation of LPG equipment in the car. LPG equipment is frequently installed in the cars running for more than $10-15$ years. 


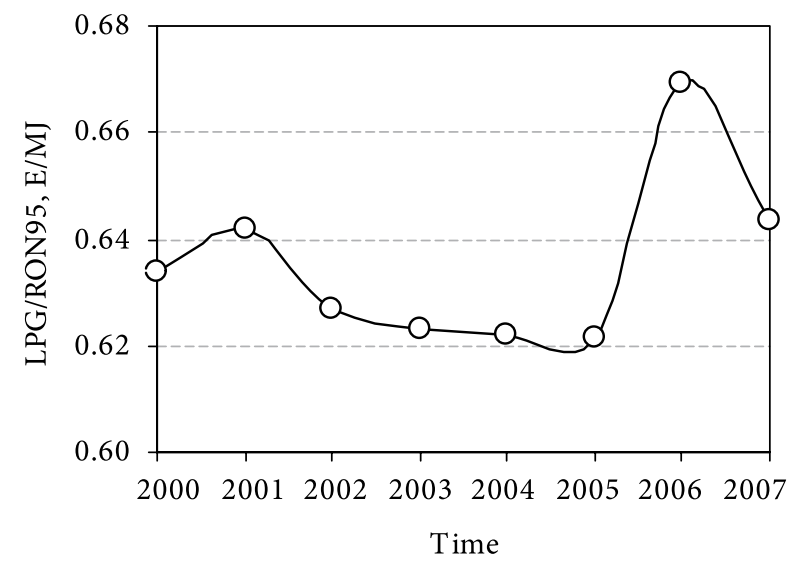

Fig. 7. Tendencies toward the prices of LPG and gasoline RON95 ratio

Table 4. The pay-off of LPG equipment

\begin{tabular}{|c|c|c|c|c|c|}
\hline Variable & 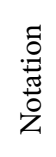 & 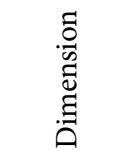 & 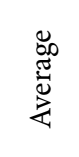 & $\dot{\Xi}$ & 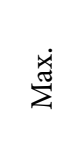 \\
\hline Gasoline consumption & $B_{G}$ & Liter $/ \mathrm{km}$ & 0.1 & 0.085 & 0.12 \\
\hline LPG installation price & $K$ & $€$ & 1500 & 750 & 2500 \\
\hline Gasoline price & $B_{k}$ & $€ /$ liter & 2.0 & 1.5 & 2.5 \\
\hline
\end{tabular}

In such cases, the pay-off of the equipment may be longer than the exploitation of the cars.

It is easy to notice that the ratio of LPG and gasoline RON95 prices $\left(X_{2}\right)$ may be expressed as the variables of equation (7):

$$
X_{2}=\frac{D_{k}}{B_{k}}=\frac{1-\frac{K}{L \cdot B_{G} \cdot B_{k}}}{S} .
$$

For a number of years, the ratio of EU fuel prices has had a tendency to fluctuate (Fig. 8). This means that the distance driven by the car has a tendency to fluctuate alike and the use of LPG equipment in the car is getting less attractive.

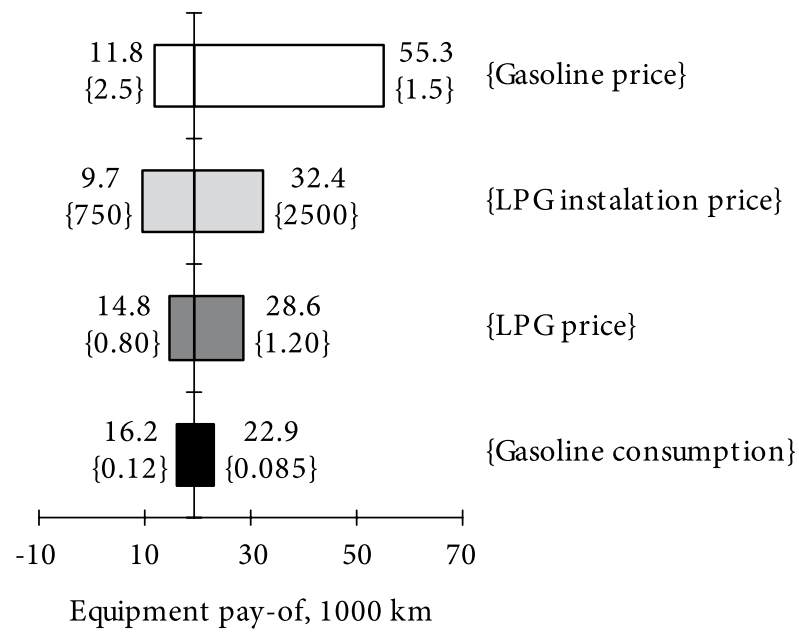

Fig. 8. Driven distance pay-off of LPG equipment

\section{Conclusions}

1. Though it is obvious that LPG in cars enables to reduce the amount of hazardous pollutants, particularly relevant in towns, however, LPG in cars is used only in some countries of the EU.

2. Under the close scrutiny of hedonic model diagnosis, LPG use in cars can be derived from a bundle of specific variables. The model can be used for predicting and understanding the relationship between response and the response and predictors.

3. The ratio of LPG and petrol prices is a promoting measure for making decision to use LPG in cars; however in order to widely use LPG in transport, LPG prices should be reduced.

\section{References}

Biderman, C.; Polenske, K.; Rockler, N. 2005. Demand and cost impacts of the $2 \mathrm{~mm}$ technology program in the US motorvehicle market, Economics of Innovation and New Technology 14(7): 637-655.

Butkus, A.; Pukalskas, S.; Bogdanovičius, Z. 2007. The influence of turpentine additive on the ecological parameters of Diesel engines, Transport 22(2): 80-82.

Directive 2003/30/EC of the European Parliament and of the Council. 2003. Official Journal of the European Union. 5 p. Available from Internet: <http://ec.europa.eu/energy/res/ legislation/doc/biofuels/en_final.pdf $>$.

EUROSTAT home page. 2008. European Commission. Available from Internet: <http://epp.eurostat.ec.europa.eu>.

Faiz, A.; Weaver, C. S.; Walsh, M. P. 1996. Air Pollution from Motor Vehicles: Standards and Technologies for Controlling Emissions. The World Bank. Washington, D. C. 266 p. Available from Internet: <http://siteresources.worldbank.org/INTURBANTRANSPORT/Resources/b02airpolution.pdf $>$.

Hung, W.-T. 2006. Taxation on vehicle fuels: its impacts on switching to cleaner fuels, Energy Policy 34(16): 2566-2571.

International Energy Agency (IEA) statistic. 2008. Energy Prices and Taxes: Quarterly Statistics. OECD. 485 p.

Johnson, E. 2003. LPG: a secure, cleaner transport fuel? A policy recommendation for Europe, Energy Policy 31(15): 1573-1577.

Kugelevičius, J. A.; Kuprys, A.; Kugelevičius, J. 2007. Forecasts of petroleum demand, Transport 22(1): 9-13.

Lingaitis, L. P.; Pukalskas, S. 2008a. Ecological aspects of using biological diesel oil in railway transport, Transport 23(2): 138-143.

Lingaitis, L. P.; Pukalskas, S. 2008b. The economic effect of using biological diesel oil on railway transport, Transport 23(4): 287-290.

McCormack, K. 2003. Diagnostics for Hedonic Models: Using an Example for Cars (Hedonic Regression) 34 p. Available from Internet: <http://www.cso.ie/surveysandmethodologies/documents/pdf_docs/hedonics.pdf $>$.

Simpson, A. G. 2005. Parametric Modeling of Energy Consumption in Road Vehicles. A thesis submitted for the degree of Doctor of Philosophy at The University of Queensland. 259 p. Available from Internet: <http://www.itee.uq.edu. au/ serl/_pamvec/PhD_Thesis_AGS_050420.pdf >.

Steppan, D.; Werner, J.; Yeater, B. 1998. Essential Regression and Experimental Design. Available from Internet: $<$ http://www. geocities.com/SiliconValley/Network/1032/>.

Tanczos, K.; Torok, A. 2007. The linkage between climate change and energy consumption of Hungary in the road transportation sector, Transport 22(2): 134-138. 